\title{
Generation of neural progenitor cells by chemical cocktails and hypoxia
}

\author{
Lin Cheng ${ }^{1, *}$, Wenxiang $\mathrm{Hu}^{1,{ }^{*}}$, Binlong Qiu ${ }^{1, *}$, Jian Zhao ${ }^{1, *}$, Yongchun $\mathrm{Yu}^{2}$, Wuqiang Guan ${ }^{2}$, Min Wang ${ }^{2}$, \\ Wuzhou Yang ${ }^{2}$, Gang Pei ${ }^{1,3}$ \\ ${ }^{I}$ State Key Laboratory of Cell Biology, Institute of Biochemistry and Cell Biology, Shanghai Institutes for Biological Sciences, \\ Chinese Academy of Sciences, 320 Yueyang Road, Shanghai 200031, China; ${ }^{2}$ Institute of Neurobiology, Institutes of Brain Science \\ and State Key Laboratory of Medical Neurobiology, Fudan University, Shanghai 200032, China; ${ }^{3}$ School of Life Science and \\ Technology, Tongji University, Shanghai 200092, China
}

Neural progenitor cells (NPCs) can be induced from somatic cells by defined factors. Here we report that NPCs can be generated from mouse embryonic fibroblasts by a chemical cocktail, namely VCR (V, VPA, an inhibitor of HDACs; C, CHIR99021, an inhibitor of GSK-3 kinases and R, Repsox, an inhibitor of TGF- $\beta$ pathways), under a physiological hypoxic condition. These chemical-induced NPCs (ciNPCs) resemble mouse brain-derived NPCs regarding their proliferative and self-renewing abilities, gene expression profiles, and multipotency for different neuroectodermal lineages in vitro and in vivo. Further experiments reveal that alternative cocktails with inhibitors of histone deacetylation, glycogen synthase kinase, and TGF- $\beta$ pathways show similar efficacies for ciNPC induction. Moreover, ciNPCs can also be induced from mouse tail-tip fibroblasts and human urinary cells with the same chemical cocktail VCR. Thus our study demonstrates that lineage-specific conversion of somatic cells to NPCs could be achieved by chemical cocktails without introducing exogenous factors.

Keywords: lineage conversion; neural progenitor cells; chemical cocktails; hypoxia

Cell Research (2014) 24:665-679. doi:10.1038/cr.2014.32; published online 18 March 2014

\section{Introduction}

Differentiated cells performing their specific functions possess phenotypic stabilities and are thought to lose developmental potency [1]. However, studies show that the nucleus of terminally differentiated cells can be used for the cloning of animals $[2,3]$, indicating that the epigenetic modifications during development are reversible. Furthermore, conversion of different cell lineages can be achieved by cell fusion in vitro [4], indicating that nuclear and cytoplasmic components can induce transcriptional reprogramming [5]. Very recently, substantial progress has been achieved with the discovery that not only pluripotent stem cells can be induced from diverse somatic

\footnotetext{
*These four authors contributed equally to this work.

Correspondences: Gang Pei ${ }^{\mathrm{a}}$ Jian Zhao ${ }^{\mathrm{b}}$

${ }^{a}$ E-mail: gpei@sibs.ac.cn

bE-mail: jzhao@sibs.ac.cn

Received 7 February 2014; revised 25 February 2014; accepted 27 February 2014; published online 18 March 2014
}

cell types with a specific set of transcription factors [6] but also direct lineage conversion with transcription factors is possible [7] in vitro, providing fundamental new strategies for disease modeling with patient-specific cells or potential direct therapeutic approaches.

Neural progenitor cells (NPCs) that are capable of self-renewing and differentiating into neural cell lineage hold great promise for both biomedical research and potential cell therapy $[8,9]$. Protocols have been standardized for primitive derivation of NPCs from brain tissues and induction of NPCs from pluripotent cells including embryonic stem cells (ESCs) and Yamanaka factor-induced pluripotent stem cells (iPSCs) [10-13]. In addition, direct lineage-specific conversion of different somatic cells to expandable neural progenitor cells by sets of defined factors provide opportunity to employ disease- or patient-specific neural cells [14-22]. However, due to the introduction of exogenous genes, there are still a lot of open questions coming along with these new techniques especially on their clinical safety concerns.

Very recent achievements in the induction of iPSCs 
from mouse somatic cells by small molecule compounds or under specific conditions provide sources for iNPCs without introducing exogenous factors [23, 24]. However, induction of NPCs from either ESCs or iPSCs is still complicated and time-consuming. Thus, a direct conversion of somatic cells to NPCs by small molecule compounds without introducing exogenous genes should provide another desirable alternative to recent available strategies.

Here we show that under $5 \% \mathrm{O}_{2}$, a physiological hypoxic condition, a series of chemical cocktails containing inhibitors of histone deacetylation, glycogen synthase kinase, and TGF- $\beta$ pathways can be applied to induce the conversion of somatic cells to NPCs. Moreover, these chemical-induced NPCs (ciNPCs) can be induced not only from mouse embryonic fibroblasts (MEFs) but also from mouse tail-tip fibroblasts (TTFs) and human urinary cells (HUCs) with the same chemical cocktail. Our study thus offers another strategy for neuroscience research and related regenerative medicine.

\section{Results}

Induction of NPCs from MEFs by a chemical cocktail VCR under physiological hypoxia

To successfully induce NPCs from differentiated cells without introducing exogenous transcriptional factors, we first hypothesized that chemicals shown to promote cell reprogramming with a preference to induce Sox 2 expression might facilitate cell transition into an intermediary stage, and then these intermediates could be induced to NPCs under lineage-specific conditions. Chemicals including VPA, CHIR99021, Repsox, Parnate, SB431542, BIX01294 and RG-108 have been shown to induce the expression of endogenous Sox2 [25-29]. Further, con- sidering that a physiological hypoxic condition has been shown to promote cell reprogramming [30], we compared different chemical combinations for their intermediary transition efficacy under physiological hypoxic $(5 \%$ $\left.\mathrm{O}_{2}\right)$ and ambient normoxic $\left(21 \% \mathrm{O}_{2}\right)$ conditions. Compact cell colonies were observed in MEFs cultured under $3 \%$ or $5 \% \mathrm{O}_{2}$ as early as 10 days after VPA, CHIR99021, Repsox and Parnate (termed as VCRP) were added to the culture medium (Supplementary information, Figure S1A). Approximately 40 compact cell colonies emerged from $2 \times 10^{5}$ MEFs. Colony induction efficiency was slightly higher under $5 \% \mathrm{O}_{2}$ compared to that under 3\% $\mathrm{O}_{2}$, thus we used $5 \% \mathrm{O}_{2}$ culture condition for our further experiments. Of these compact cell colonies formed under $5 \% \mathrm{O}_{2}$, about $3 / 4$ colonies expressed high levels of alkaline phosphatase (AP) (Supplementary information, Figure S1B). Neither compact cell colony nor AP activity was observed in MEFs treated with VCRP under normoxia.

We then tested whether VPA, CHIR99021, Repsox and Parnate are all required for compact cell colony formation. For this, we treated MEFs with combinations lacking only one individual molecule of the VCRP set and monitored the compact cell colony formation. We found that Parnate was dispensable for compact cell colony formation, while withdrawal of Repsox, CHIR99021 or VPA from the cocktail significantly reduced the number of compact cell colonies (Supplementary information, Figure S2A). About 90\% colonies induced by VCR (VPA, CHIR99021, Repsox) under 5\% $\mathrm{O}_{2}$ expressed high levels of AP (Figure 1A). Further supplement of the VCR set with any other reprogramming-promoting compound [31-33] showed no significant improvement (Supplementary information, Figure S2B).

We monitored the expression of pluripotency-related

Figure 1 Induction of ciNPCs from MEFs by a chemical cocktail VCR under physiological hypoxic condition. (A) Induction of AP-positive compact cell colonies by VCR under hypoxia. MEFs were cultured under $21 \%$ (normoxia) or $5 \%$ (hypoxia) $\mathrm{O}_{2}$ in the presence of VCR (0.5 mM VPA, $3 \mu \mathrm{M}$ CHIR99021 and $1 \mu \mathrm{M}$ Repsox). Representative pictures of compact cell colonies and colonies stained with alkaline phosphatase (AP) were shown. Colonies were counted on day 15 following VCR treatment. Bars represent the number of colonies per 200000 cells initially plated. (B) Relative expression levels of pluripotencyrelated genes were measured by quantitative RT-PCR and shown. All sample data are normalized to that of day 0 , which is considered as 1. (C) Induction of NPC-like cells from VCR-treated MEFs. VCR-treated MEFs were cultured in neural expansion medium. Representative images of MEFs and ciNPCs at passages 1, 5 and 13 were shown as indicated. (D) Relative expression levels of NPC-specific genes were monitored by qRT-PCR and shown. All sample data are normalized to that of MEFs, which is considered as 1. (E) Expression of Nestin, Pax6 and Sox2 was visualized by immunostaining. Nuclei were counterstained with DAPI. Representative images were shown. Nestin/Pax6 or Nestin/Sox2 double positive cells were counted and shown in right panel. (F) Scheme of the experimental strategy for induction of ciNPCs from mouse fibroblasts. Generally, initial fibroblasts were plated in DMEM and this day is termed as "Day -2 ". 2 days later, cells were transferred into KSR medium with chemical compounds and cultured under $5 \% \mathrm{O}_{2}$. Compact cell colonies formed in about 10 days. Cell mixtures containing colonies were then further cultured in neural expansion medium with growth factors. ciNPCs formed around day 20 were further enriched by rounds of neurosphere suspension culture. Scale bars represent $50 \mu \mathrm{m}$. Data are represented as the mean \pm SEM. At least three independent experiments were performed. ${ }^{* * *} P<0.001,{ }^{* *} P<0.01$. 

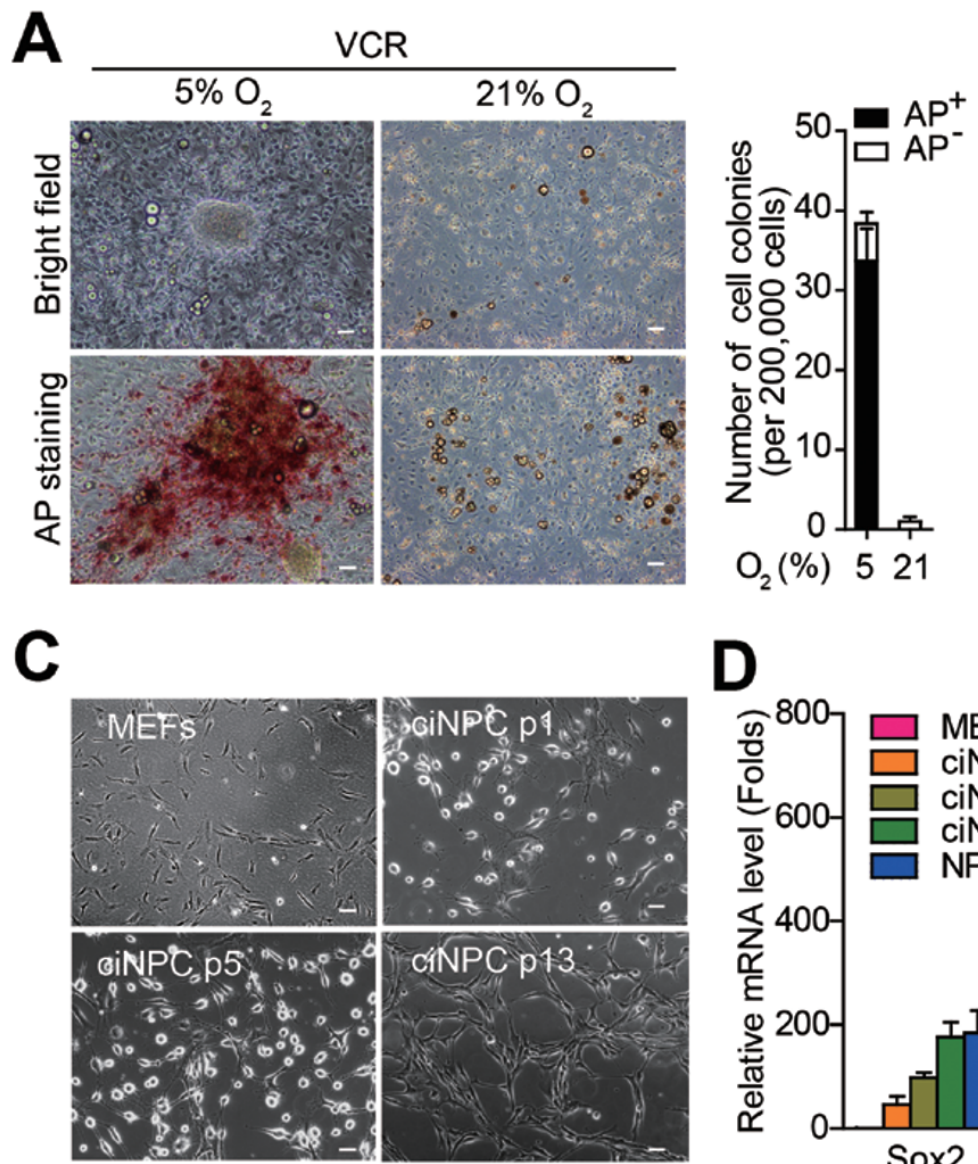

B
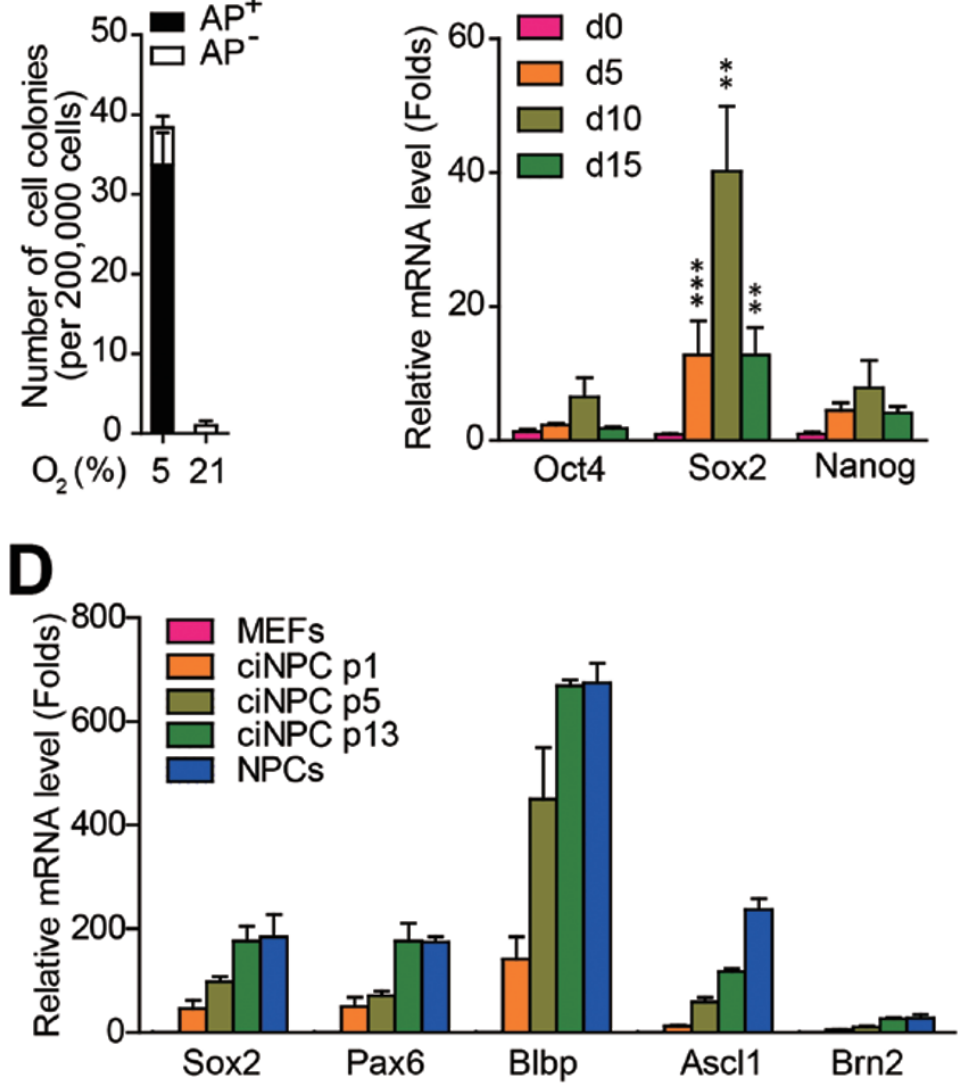

E
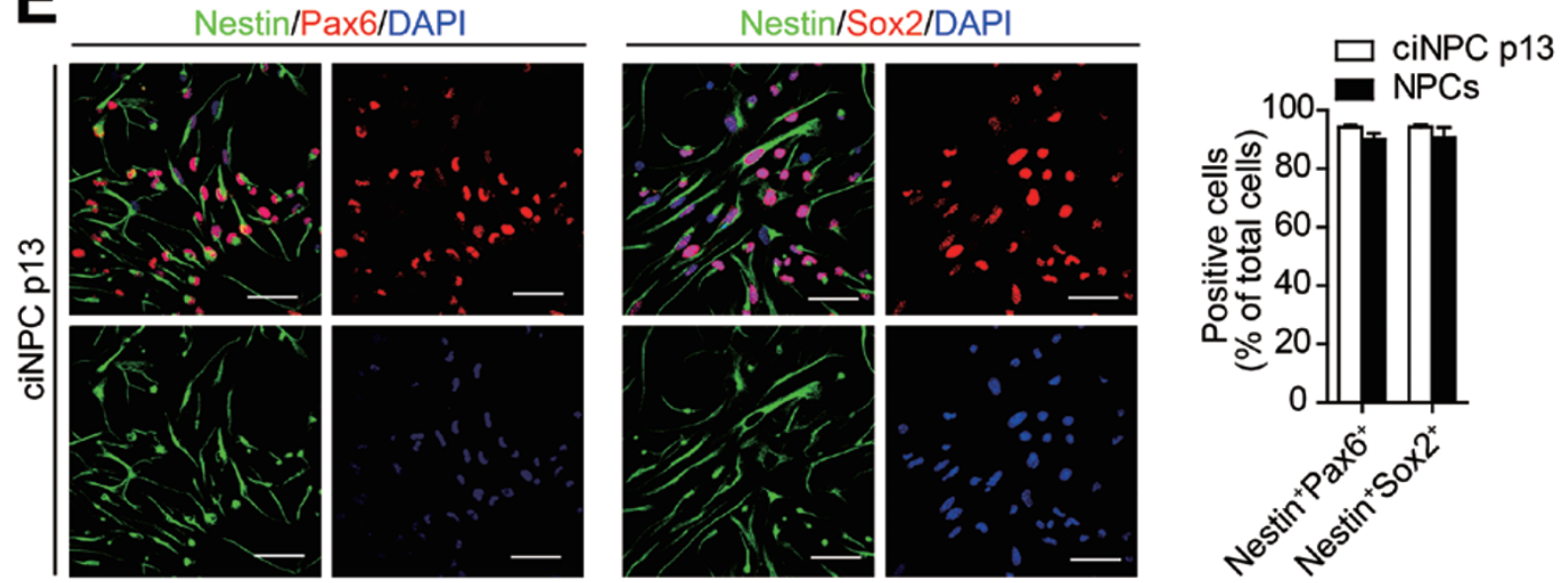

F Fibroblasts

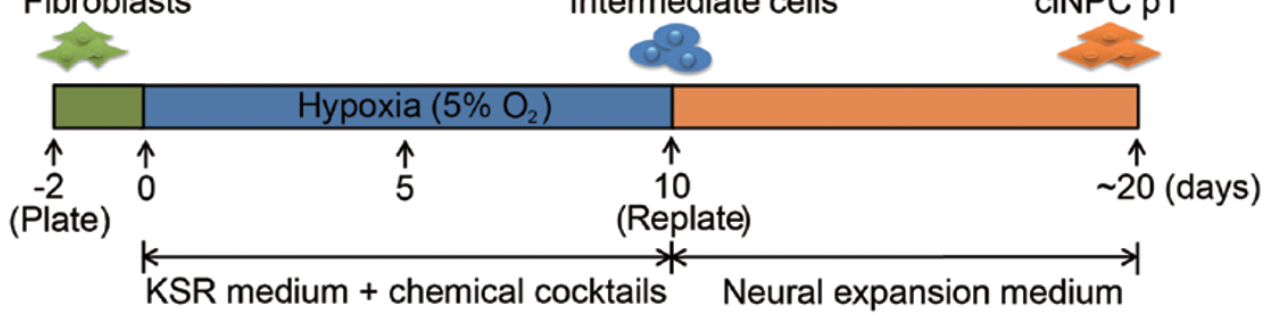


genes by reverse transcription-coupled quantitative realtime PCR (qRT-PCR) analysis. As shown in Figure 1B, in cells treated with VCR under hypoxic condition, the expression of Sox 2 significantly increased on day 5, peaked on day 10 and then declined on day 15, whereas the expression of Oct4 and Nanog was slightly induced on day 10. On the other hand, under normoxic condition or with any chemical sets lacking Repsox, CHIR99021 or VPA, expression of Sox 2 could not be efficiently induced (Supplementary information, Figure S2C and $\mathrm{S} 2 \mathrm{D})$. Together, these results indicate that the small molecule cocktail VCR facilitates the transition of MEFs to intermediary compact cell colonies under $5 \% \mathrm{O}_{2}$ condition.

Next we tested whether these compact cell colonies would further develop into NPCs under lineage-specific culture conditions. Cells that were treated with VCR under hypoxia for 10 days were replated and cultured in neural expansion medium (NEM) supplemented with heparin, epidermal growth factor (EGF) and basic fibroblast growth factor (bFGF). 7-10 days later, an NPClike bipolar morphology with extended processes was observed in cultured cells (Figure 1C). NPC markers including Nestin, Sox 2 and Pax6 began to express as detected by immunofluorescent staining (Supplementary information, Figure S3A). Further, the expression levels of NPC-specific genes including Sox2, Pax6, Blbp, Ascl1 and $B r n 2$ were enhanced as quantified by real-time RTPCR analysis (Figure 1D), indicating the emerging of NPC-like cells in our culture. Moreover, when these cells were cultured further in suspension, free-floating clusters formed. These free-floating clusters stained positive for Sox 2 and Nestin, which are the characteristics of neurospheres (Supplementary information, Figure S3A). We collected these free-floating clusters and referred them as ciNPC passage 1 (p1).

\section{Proliferation and self-renewal of ciNPCs}

We then tried to culture these ciNPC neurospheres in suspension to examine whether these ciNPCs possess two fundamental characteristics of NPCs, i.e., proliferation and self-renewal $[34,35]$. After being cultured for four passages, around $50 \%$ of ciNPCs were stained positive for Sox 2 , more than $60 \%$ cells were Pax6 positive, about $40 \%$ were Nestin positive, while about $30 \%$ cells were Nestin/Pax6 or Nestin/Sox2 double positive (Supplementary information, Figure S3B). ciNPCs from passage 13 plated as monolayer showed morphologies very similar to mouse embryonic NPCs (Figure 1C). Quantitative analysis of the expression patterns of Sox2, Pax6, Ascll, Blbp and Brn2 of ciNPCs from different passages confirmed that the suspension culturing procedure suc- cessfully enriched NPCs from the primary induced cell mixture (Figure 1D). At passage 13, more than $96 \%$ of total ciNPCs were stained positive for Nestin, Sox 2 and Pax6 individually and about $93 \%$ of ciNPCs expressed both Nestin/Sox2 or Nestin/Pax6 (Figure 1E and Supplementary information, Figure S4), indicating that a highly homogenous population has formed (Figure 1F). Moreover, not only that these ciNPCs from p13 were stained positive for the proliferation marker Ki67 (Figure 2A), but also when seeded at low density, the size and number of neurospheres formed from ciNPC p13 were comparable to that formed from mouse brain-derived NPC passage 5 (Figure 2B), indicating that these ciNPCs have very similar proliferation and self-renewal profiles as mouse brain-derived NPCs.

The proliferation potency of the ciNPCs was continuously monitored during further culture. The expression patterns of NPC markers and the ability to form neurospheres in suspension did not alter up to passage 25 (Figure 2C and 2D). Together, our results indicate that a homogenous expandable ciNPC population resembling NPC properties can be obtained from MEFs by VCR treatment under hypoxia.

\section{ciNPCs show similar transcription profiles as NPCs}

To access the exact identity of ciNPCs, we extracted mRNA from mouse brain-derived NPCs (as control NPCs), MEFs, ciNPCs at passage 5 and passage 13 and compared the global gene expression patterns of these cells by microarray analysis. The global genome heat map with hierarchical cluster analysis (Figure 3A) and scatter plot analysis (Figure 3B) revealed a significant difference between ciNPCs and parental MEFs, and a high degree of similarity between ciNPCs and control NPCs. The shared core targets of ciNPCs from different batches and control NPCs included 774 genes (Figure 3C), which were primarily related to neural processes and cell morphogenesis, based on gene ontology (GO) function enrichment analysis (Figure 3D and Supplementary information, Figure S5A). Expression of neuralspecific genes, such as Sox2, Pax6, Ncan, Tox3, Hes5, Gpm6a, Nes, Bmil, Zbtb16, Rfx4, Gpm6a and Slcla3 [19], was significantly upregulated in ciNPCs and was comparable to that of NPCs. However, pluripotency-related genes Pou5f1 and Nanog were not activated (Supplementary information, Figure S5B). Expression profiles of genes for biological processes related to skeletal systems were the most downregulated GO items in ciNPCs versus that in MEFs (Supplementary information, Figure S5C and S5D). Expression of a subset of 424 genes, such as Col3a1, DKK3, Thy1, Snail1 and other fibroblast-specific genes [36], was gradually downregulated from passage 
A
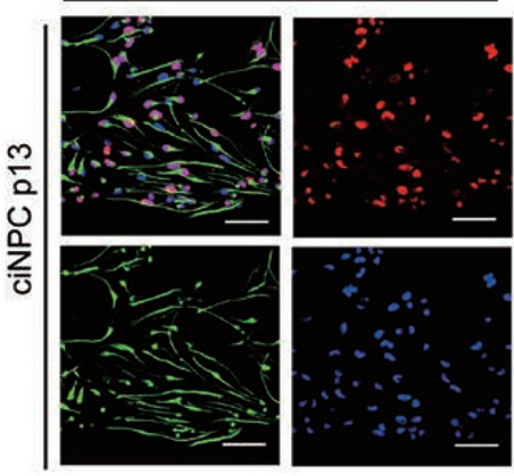

C
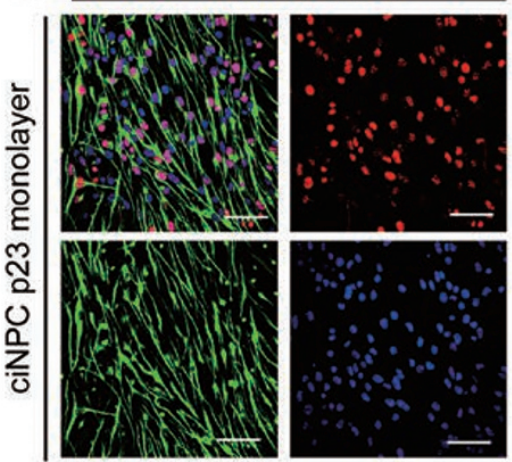

D

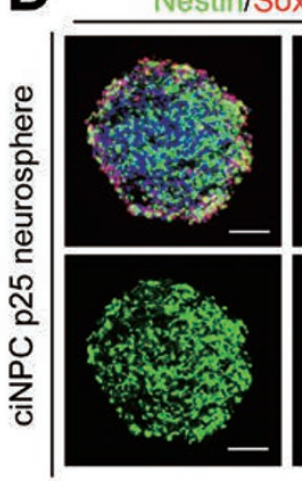

B
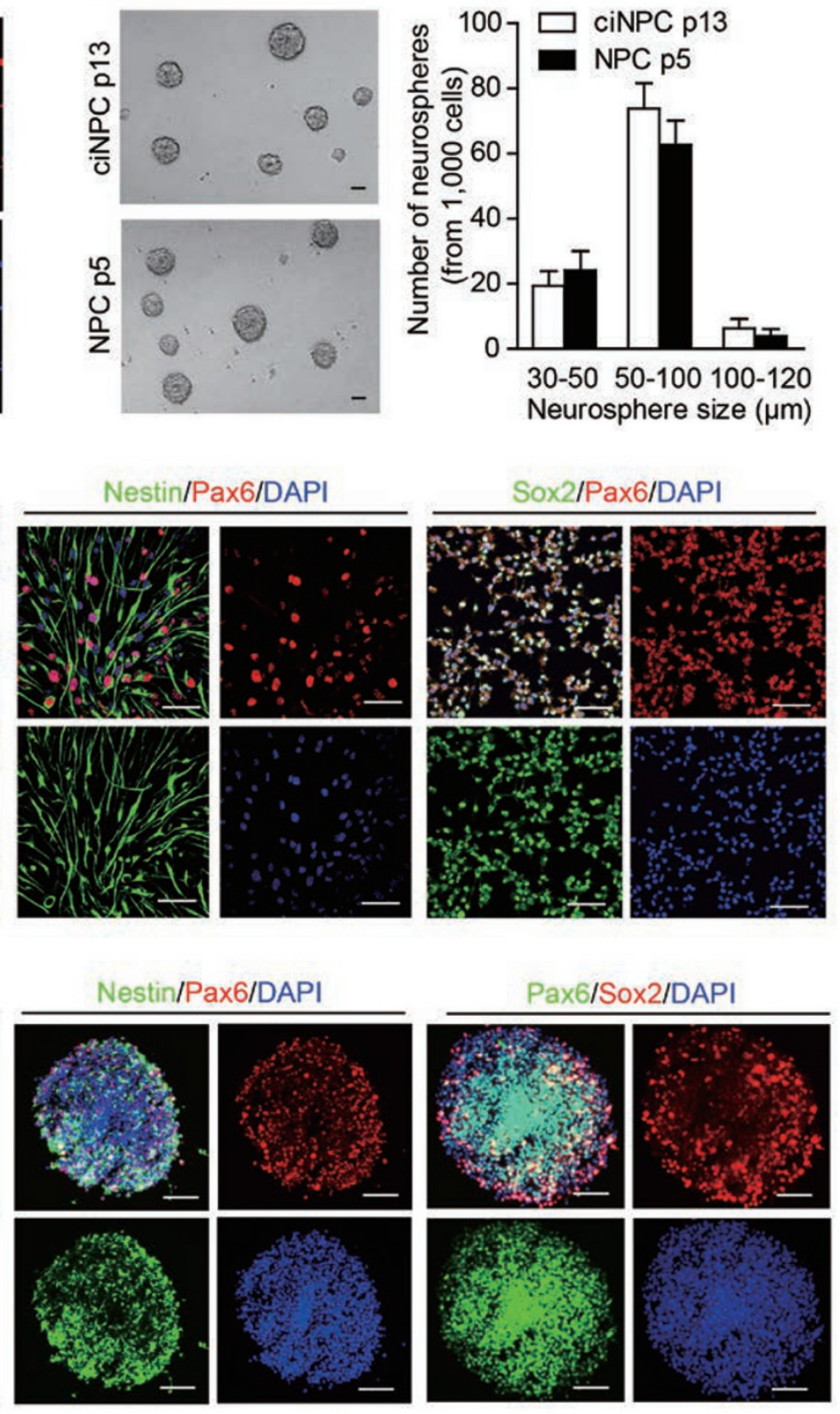

Figure 2 Proliferation and self-renewal of ciNPCs. (A) Representative images of ciNPCs at passage 13 stained for Ki67 and Nestin. (B) Neurospheres of ciNPCs at passage 13 versus those of NPCs at passage 5 cultured in suspension. (C) Nestin, Pax6 and Sox2 expression of ciNPCs at passage 23 in monolayer. (D) Nestin, Pax6 and Sox2 expression of ciNPC neurospheres at passage 25. Nuclei were counterstained with DAPI. Scale bars represent $50 \mu \mathrm{m}$. Representative images from at least three independent experiments were shown.

5 to 13 of ciNPCs. The findings that ciNPCs from MEFs retain residual fibroblast epigenetic memory exclude the possible contamination of NPCs in the initial MEF populations. On the other hand, MEFs which have been cultured directly in DMEM or NEM did not show detectable expression of Nestin, Sox2 or Pax6 (Supplementary information, Figure S6).

To examine the regional identity of these ciNPCs, we analyzed the expression of brain region-specific genes from the microarray data (Supplementary information, Figure S5E). While both ciNPCs and control NPCs exhibited high expression of ventral brain-specific Olig2 
and $N k x 2.2$ [37], there was no detectable expression of dorsal brain markers, such as $\operatorname{Pax} 3$ [38] and $\operatorname{Pax} 7$ [39], in either ciNPCs or control NPCs. We found that forebrain markers Emx2, Foxg1, Nr2el [40] and midbrain marker Gbx2 and En1 [41] were highly expressed, but there was no expression of posterior brain markers $\mathrm{Hoxa}_{7}$ and Hoxb7 [14] in ciNPCs. Together, the ciNPCs are mostly compatible with ventral fore/midbrain regionalization, but not closely correlated with specific regional identities in brain.

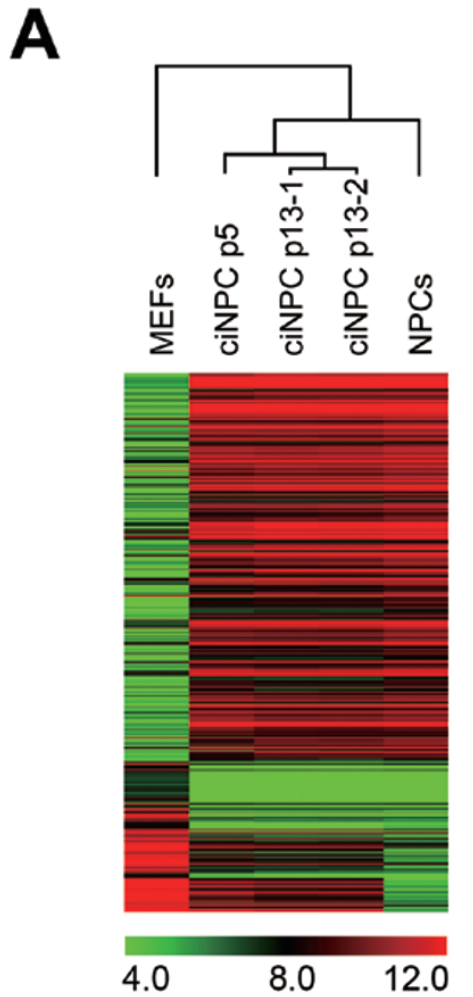

C

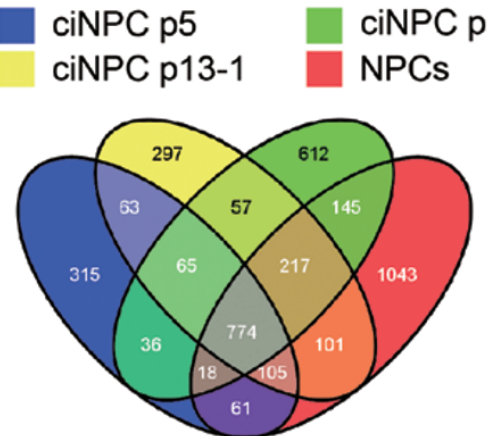

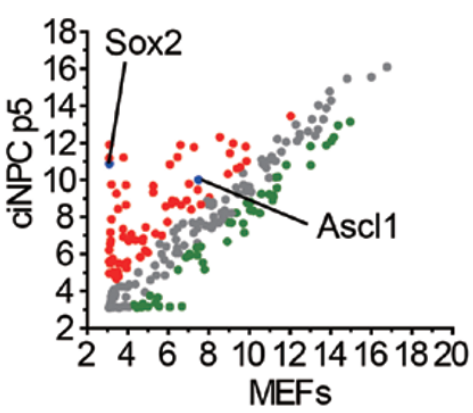
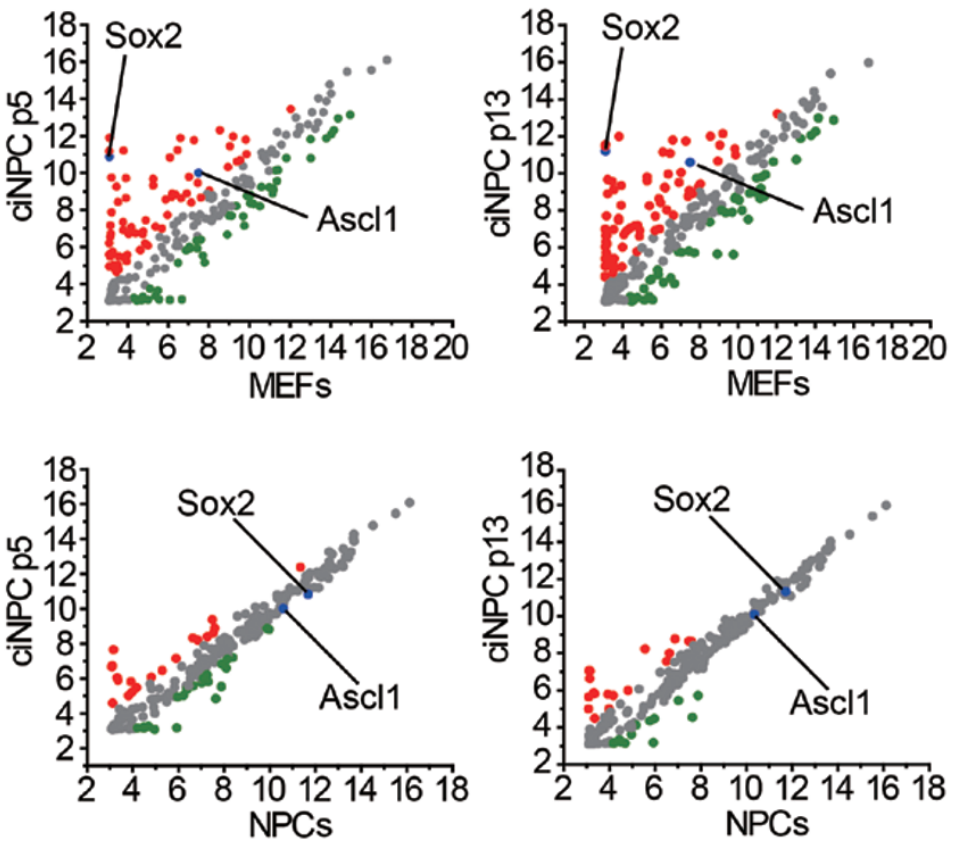

D

13-2

cell morphogenesis involved in differentiation cell morphogenesis involved in neuron differentiation

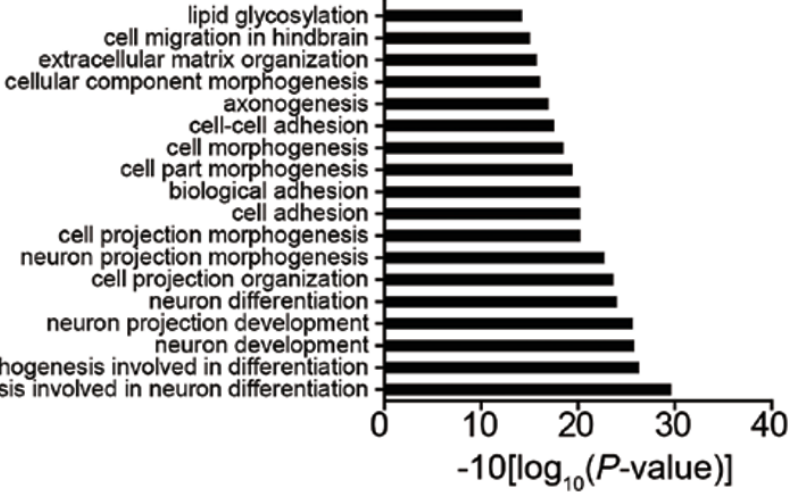

Figure 3 Genome-wide transcriptional profiling of ciNPCs. (A) Heatmap and hierarchical clustering of genes with significance from microarray analysis data. Samples of MEFs, NPCs, ciNPCs at passages 5 and 13 were compared. In heatmap, red indicates increased expression whereas green stands for decreased expression as compared to that in the MEF control sample. (B) Pairwise scatter plot analysis of 251 genes selected by the term "neuro" in the microarray data of ciNPCs p5 and p13 versus that of MEFs and NPCs. Red dots represent upregulated gene expression, whereas green dots represent downregulated ones, and the grey dots stand for no significant difference. (C) A Venn diagram illustrating the overlaps among the expression changes ( $\geq 10$-fold, $P<0.05$ ) identified in ciNPC p5, p13-1, p13-2 and control NPCs compared with that of MEFs. (D) Gene ontology (GO) analysis of the 774 overlapping genes in $\mathbf{C}$. The $P$ values represent the EASE scores. 
We further analyzed expression patterns of genes that are related with histone deacetylases (HDACs), glycogen synthase kinase 3 (GSK-3), TGF- $\beta$ signal pathways and hypoxia. Interestingly, in ciNPCs and control NPCs, genes that are known to be subjected to regulation by these pathways show very similar expression patterns, which are significantly different from that in MEFs (Supplementary information, Figure S7). These data suggest that activation of a defined set of genes by coordination of these pathways is required for the successful transition of MEFs into ciNPCs.

\section{ciNPCs show multipotency in vitro and in vivo}

The third fundamental characteristic of NPCs is their multipotency [34, 42]. The multipotency of ciNPCs was assessed by culturing cells under neuronal or glial differentiation conditions. We found that 7 days after being plated, $\sim 90 \%$ cells of ciNPCs p5 or p13 become GFAP (glial fibrillary acidic protein)-positive with astrocytelike morphology in N2B27 medium with BMP4 and 1\% FBS and $\sim 80 \%$ cells of ciNPCs become Tuj1-positive with neuron-like morphology in neural basal medium with B27, N2, BDNF, GDNF, IGF, cAMP and ascorbic acid. 10-14 days after plating, MAP2 and Tuj1 double positive cells with neuron-like morphology were found in culture (Supplementary information, Figure S8A and Figure 4A). MAP2 or Tuj1 was never found in GFAPpositive cells. We then induced the differentiation of ciNPCs with more defined differentiation protocols. ciNPCs at passage 13 were cultured in medium containing bFGF, PDGF-AA and T3. Within about 12 days, Olig2 ${ }^{+} / \mathrm{Mbp}^{+}$ cells with morphological characteristics of oligodendrocytes were observed in culture (Figure 4A, differentiation efficiency $\sim 25 \%$ ). After being cultured in neural differentiation medium for 4 weeks, Tuj1-positive mature neurons began to display either glutamate or GAD67 immunoreactivity (Figure 4B and Supplementary information, Figure S8B), indicating that these ciNPCs can be induced to generate glutamatergic or GABAergic neuron populations.

The maturity and function of finally differentiated neurons from ciNPCs were further accessed by wholecell patch-clamp experiments. We observed that ciNPCderived neurons generated repetitive action potential trains (Figure 4C) and exhibited postsynaptic current spontaneously (Figure 4D). Besides, opening of voltagedependent $\mathrm{Na}^{+}$channels was also recorded from these neurons (Figure 4E). Together, these results indicate that ciNPCs are capable of differenting into main neural lineages, including astrocytes, neurons and oligodendrocytes in vitro.

Then we tried to transplant ciNPCs to assess the de- velopmental potential of these cells in vivo. We infected ciNPC p17 with pseudo lentiviral vector carrying GFP genes before transplantation. The resulted GFP-ciNPCs show no detectable alteration in their NPC-related properties, including proliferation capabilities, neurosphere formation, expression of NPC genes and in vitro multipotency (Supplementary information, Figure S9). GFPciNPCs were injected to brains of E13.5 pups. Immunofluorescent images show that GFP-ciNPCs were able to survive and migrate into diverse brain sections of pups 1 week after transplantation (Supplementary information, Figure S10A). We also observed that many of the GFPpositive cells could be labeled with antibody against Ki67, Olig2 or GFAP, but not Tuj1 (Supplementary information, Figure S10B and S10C). Furthermore, in the grafts 1 month after transplantation, Olig2 ${ }^{+}$or $\mathrm{Mbp}^{+}$ oligodendrocytes, $\mathrm{GFAP}^{+}$astrocytes and $\mathrm{NeuN}^{+}$or Tuj $1^{+}$ mature neurons derived from GFP-ciNPCs were still detectable (Figure 4F and Supplementary information, Figure S10D). These results demonstrate that engrafted ciNPCs could give rise to different neural lineage cells in vivo. We found that no GFP-labeled cells were Ki67 positive 1 month after transplantation (Supplementary information, Figure S10E). No tumor was formed in brains transplanted with GFP-ciNPCs, indicating the safety of these chemically-induced NPCs for potential therapeutic application.

\section{Induction of ciNPCs by alternative chemical cocktails}

VPA, CHIR99021 and Repsox function as inhibitors of HDACs, GSK-3 and TGF- $\beta$ kinase pathways, respectively $[25,27,43]$. Here we further investigated whether combinations of other inhibitors of these pathways could also facilitate the induction of ciNPCs. For example, whether sodium butyrate $(\mathrm{NaB})$ or Trichostatin A (TSA) could replace VPA, Lithium chloride $(\mathrm{LiCl})$ or lithium carbonate $\left(\mathrm{Li}_{2} \mathrm{CO}_{3}\right)$ could substitute CHIR99021, or Repsox may be replaced with SB431542 or Tranilast (Supplementary information, Table S1). We used the same induction protocol that is used for VCR induction. We found that under our experimental conditions, chemical cocktails NLS (combination of $\mathrm{NaB}, \mathrm{LiCl}$ and SB431542) and TLT (combination of TSA, $\mathrm{Li}_{2} \mathrm{CO}_{3}$ and Tranilast) were capable of inducing compact cell colonies with activated Sox 2 expression in MEFs under 5\% $\mathrm{O}_{2}$ (Figure 5A). These intermediary cells induced by NLS or TLT treatment under hypoxia generated Nestin ${ }^{+} /$ $\mathrm{Pax}^{+}$, or $\mathrm{Nestin}^{+} / \mathrm{Sox}^{+}$ciNPCs upon further culture in NEM (Supplementary information, Figure S11). Homogenous ciNPC populations with typical NPC morphology and neurosphere-forming ability could be obtained at passage 13 from both NLS and TLT treated MEFs (Fig- 

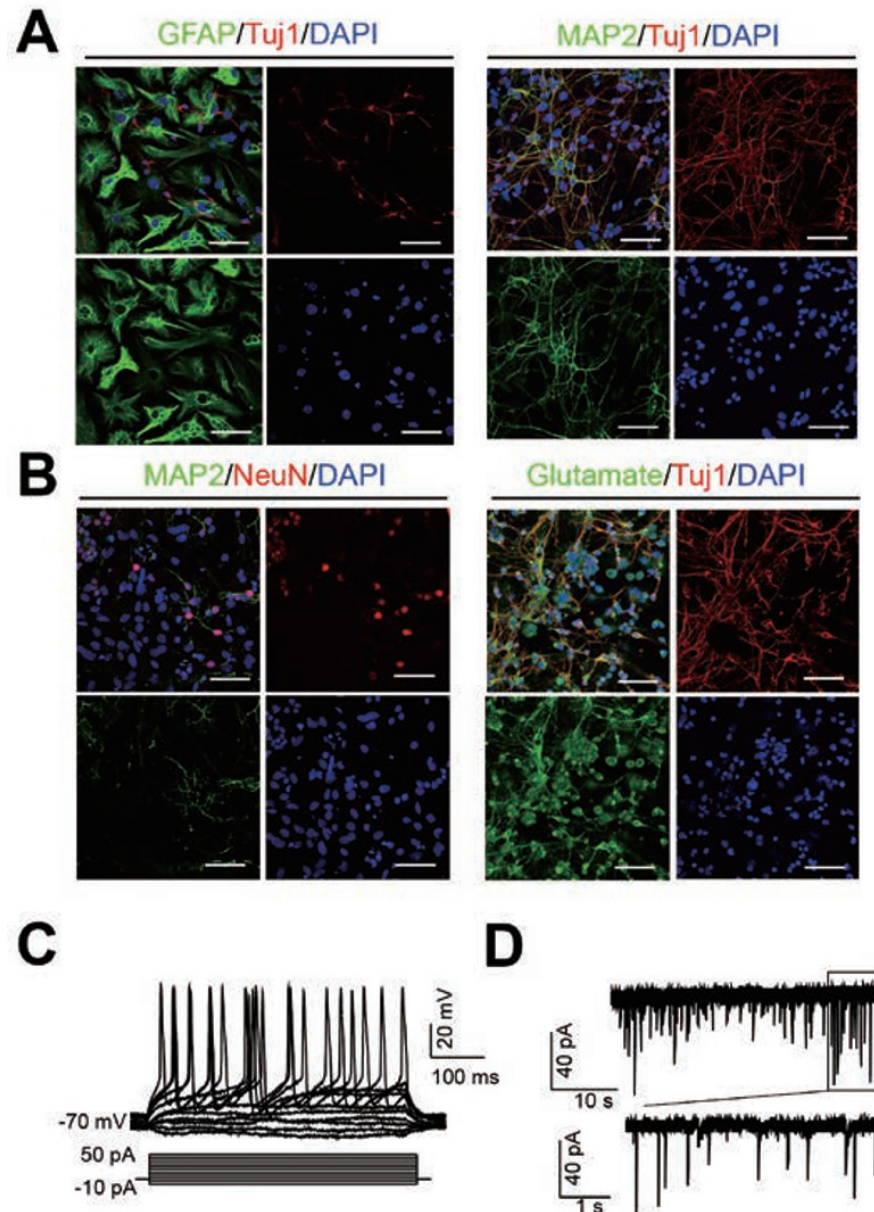

Glutamate/Tuj1/DAPI
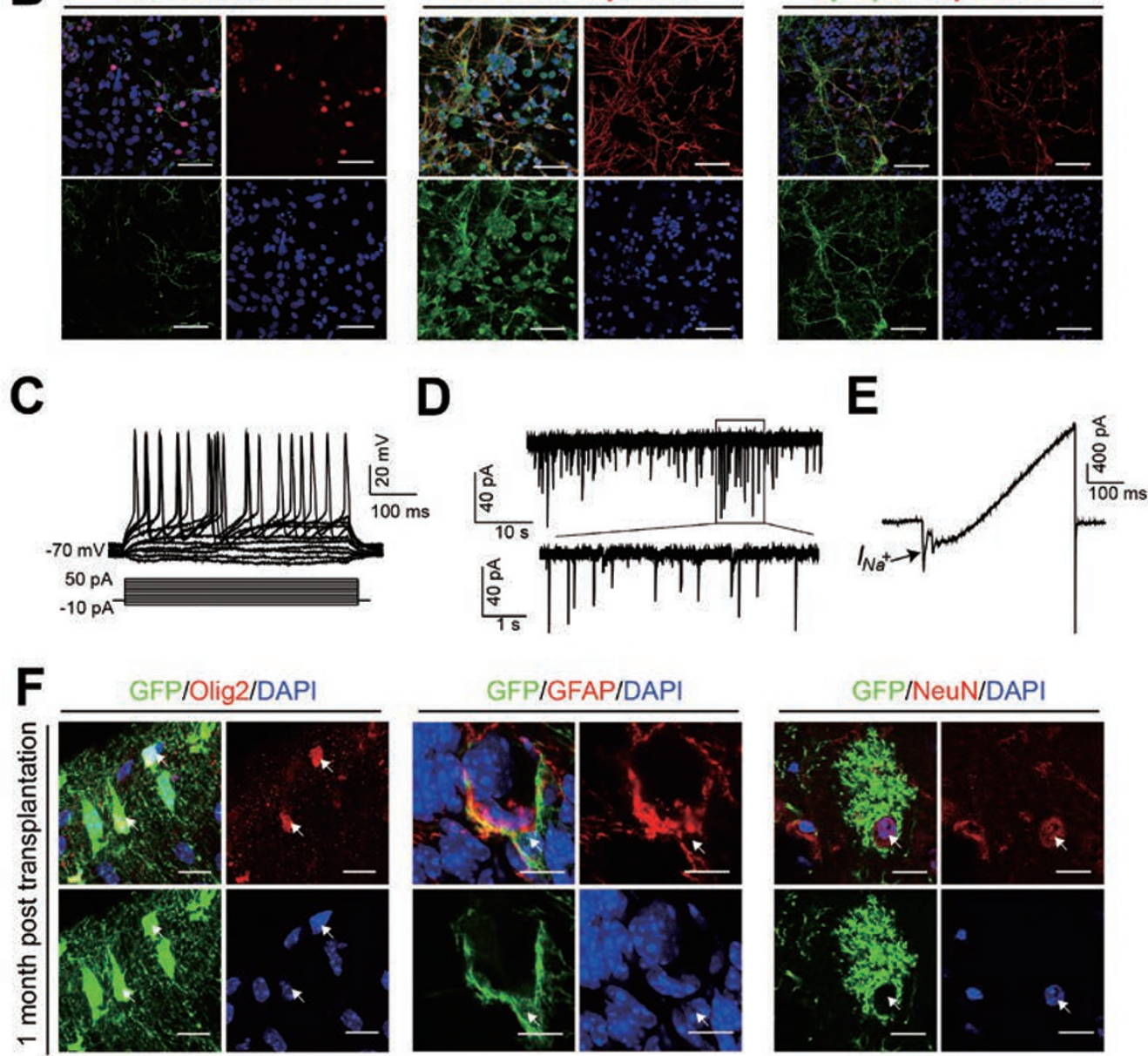

Figure 4 Multipotency of ciNPCs in vitro and in vivo. (A) Expression of marker genes GFAP (astrocyte), Tuj1 (neuron), MAP2 (neuron), Olig2 (oligodendrocyte) and Mbp (oligodendrocyte) in ciNPC p13 cultured in differentiation medium. (B) ciNPC p13 differentiation using the neuronal differentiation medium for 4 weeks were stained with neuronal markers Tuj1, NeuN, synapsin, and glutamate, a marker for glutamatergic neuron. Nuclei were counterstained with DAPI. Representative images from at least three independent experiments were shown (A, B). (C) Current-clamp recordings of neurons derived from ciNPCs showing a representative train of action potentials with stepwise current injection. (D) Representative traces of spontaneous postsynaptic currents in ciNPC-derived neurons. (E) Voltage-clamp recordings of neurons derived from ciNPCs revealing functional voltage-dependent $\mathrm{Na}^{+}$channels. Data are representatives of at least three independent experiments (C-E). (F) Olig2 ${ }^{+}$oligodendrocytes, GFAP ${ }^{+}$astrocytes, and $\mathrm{NeuN}^{+}$neurons derived from GFP-ciNPCs in vivo 1 month after transplantation. GFP-ciNPCs were transplanted to brains of E13.5 pups. One month after transplantation, the brain sections at the implantation sites were collected and subjected to immunostaining. 24 pups were transplanted with GFP-ciNPCs. Representative images were shown. Arrows indicate GFP ${ }^{+}$cells expressing Olig2, GFAP or NeuN. Nuclei were counterstained with DAPI. Scale bars represent $50 \mu \mathrm{m}$ in $\mathbf{A}$ and $\mathbf{B}, 15 \mu \mathrm{m}$ in $\mathbf{F}$. 
ure 5B). Immunofluorescent staining results showed that a high percentage of ciNPCs induced by NLS- or TLTtreatment expressed NPC marker genes Nestin, Sox 2 and Pax6. Expression levels of NPC-specific genes were further confirmed by quantitative RT-PCR analysis (Figure 5C). The observation that NLS and TLT show similar efficacy as VCR in conversion of MEFs into ciNPCs under hypoxic conditions further supports our finding from the cDNA microarray analysis that activation of a defined set of genes by coordination of these pathways plays central roles in the successful transition of MEFs into NPCs.

\section{Generation of ciNPCs from mouse TTFs and HUCs}

Then we assessed whether ciNPCs could be generated from different somatic cells or cells from different species with similar strategies. We treated neonatal mouse TTFs with the chemical cocktail VCR. As shown in Figure 6A, expression of Sox 2 was upregulated 10 days
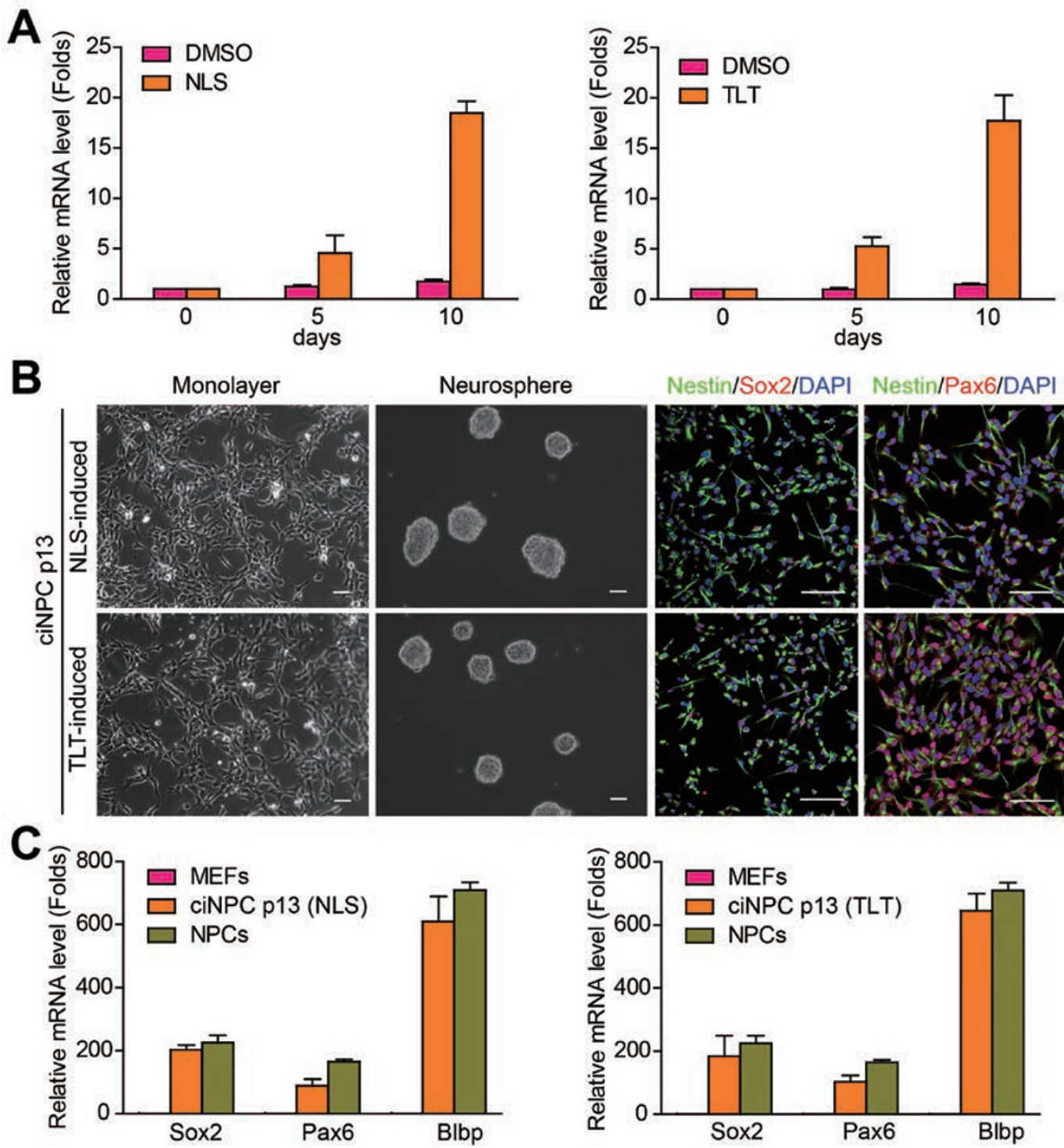

eurosphere
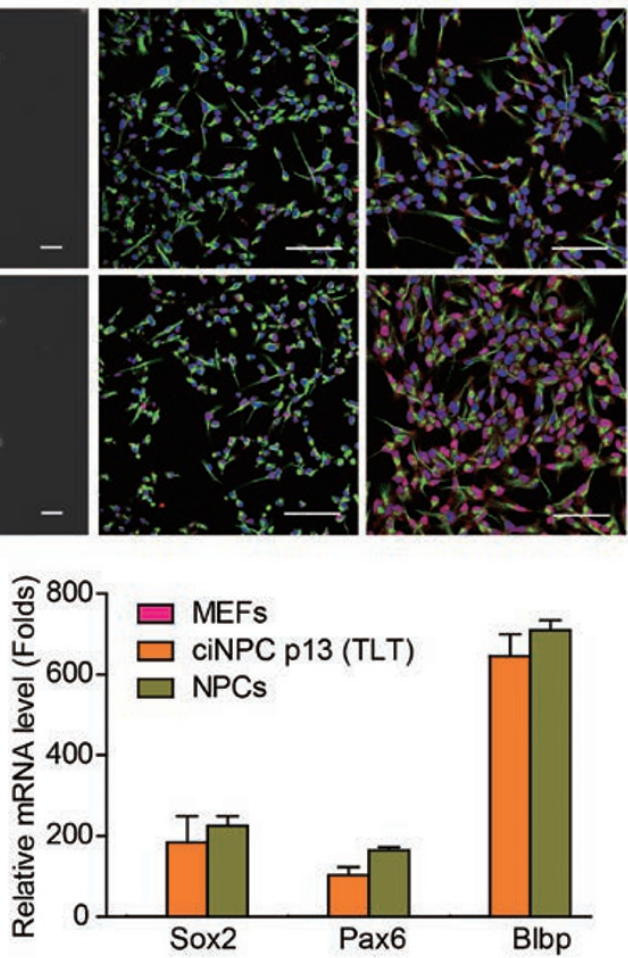

Figure 5 Induction of ciNPCs by alternative chemical cocktails. (A) qRT-PCR analysis of Sox2 expression in MEFs treated with NLS $\left(0.5 \mathrm{mM} \mathrm{NaB}, 1 \mathrm{mM} \mathrm{LiCl}\right.$ and $1 \mu \mathrm{M}$ SB431542) (left) or TLT (10 nM TSA, $0.3 \mathrm{mM} \mathrm{Li}_{2} \mathrm{CO}_{3}$ and $30 \mu \mathrm{M} \mathrm{Tranilast)} \mathrm{(right)}$ under $5 \% \mathrm{O}_{2}$. All sample data are normalized to that of cells treated with DMSO at d0, which is considered as 1. (B) Morphology and expression of Nestin, Sox 2 and Pax6 in ciNPC at passage 13 induced by NLS or TLT. Nuclei were counterstained with DAPI. Scale bars represent $50 \mu \mathrm{m}$. Representative images from at least three independent experiments were shown. (C) Relative expression levels of NPC-specific genes were monitored by qRT-PCR and shown. All sample data are normalized to that of MEFs, which is considered as 1 . Data are represented as the mean \pm SEM. 
A

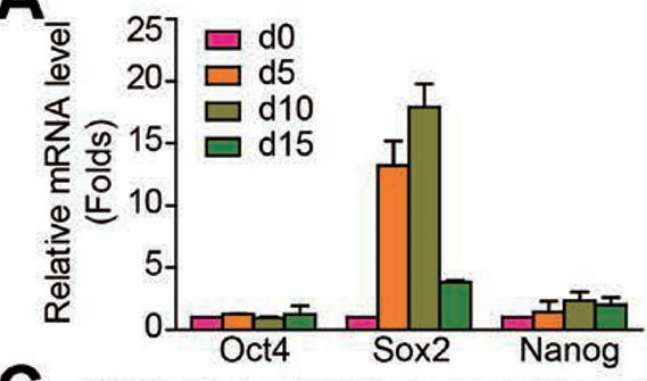

B
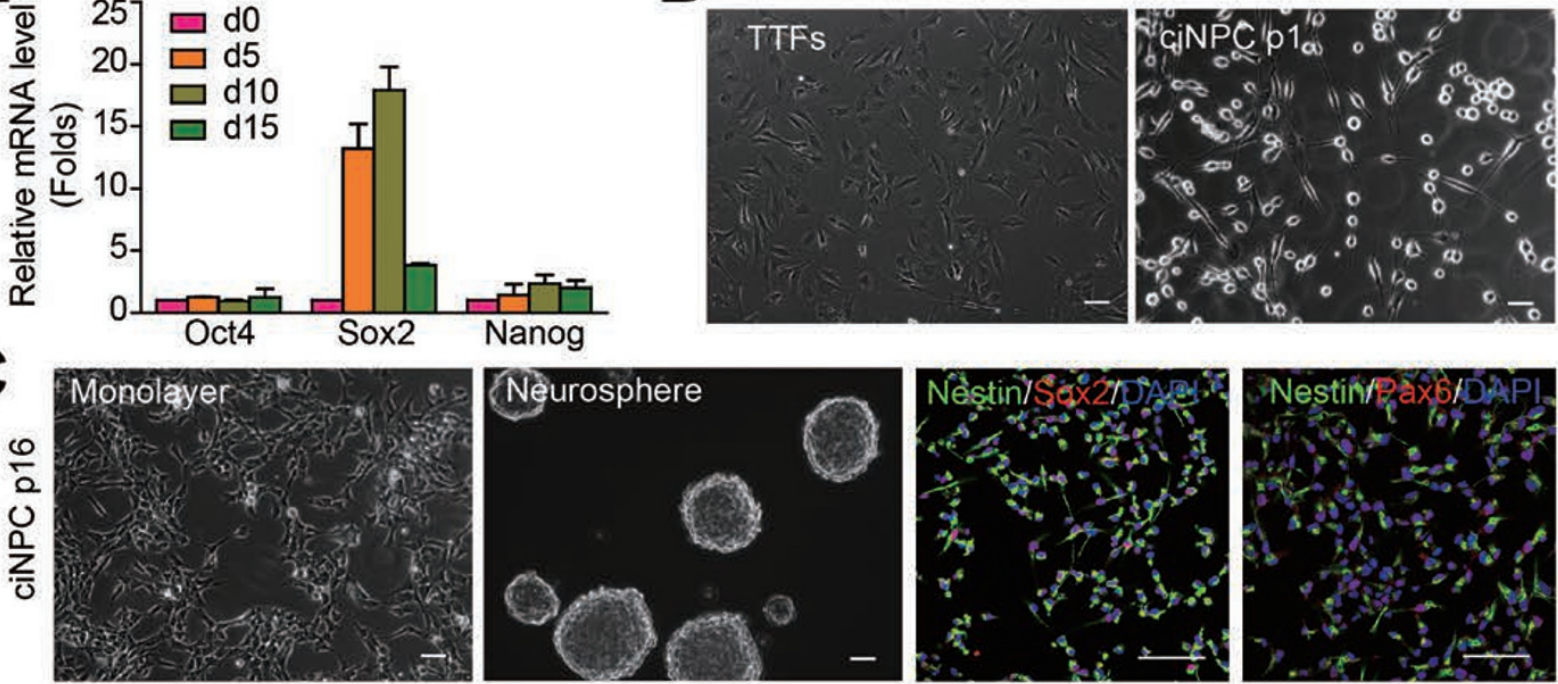

$\rightarrow$

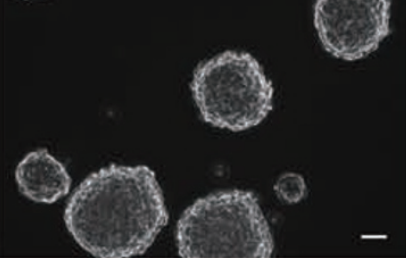

D

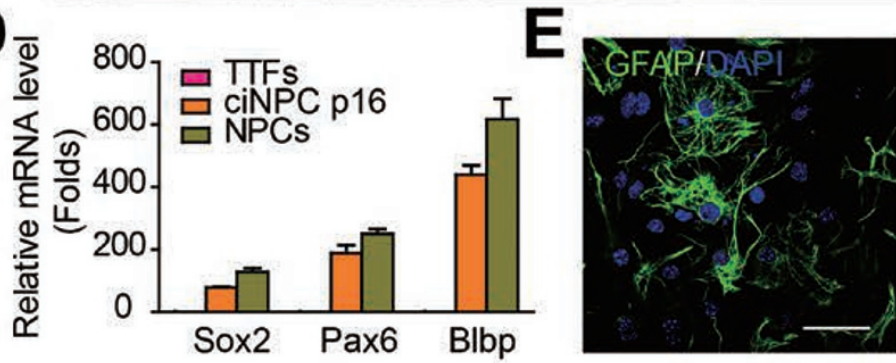

$\mathbf{F}$

$\mathrm{VCR}+5 \% \mathrm{O}_{2}$
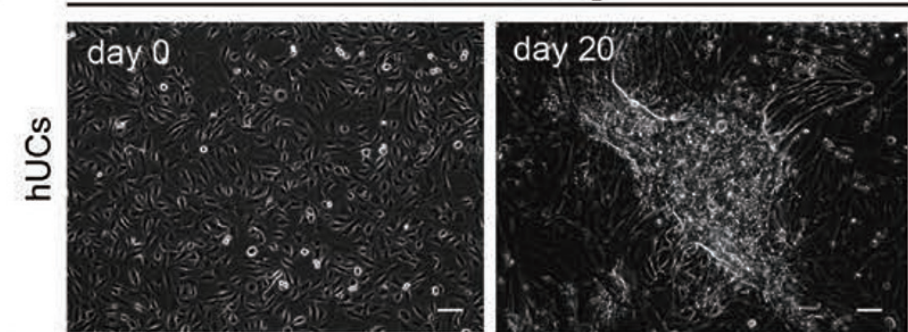

H
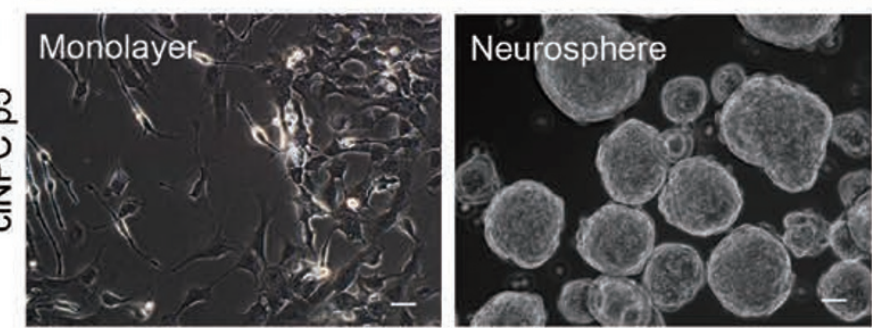

I

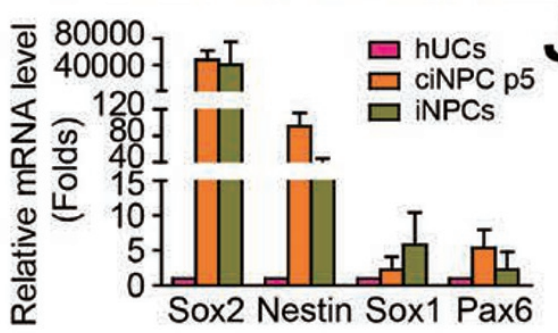

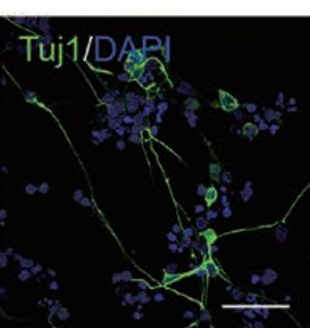
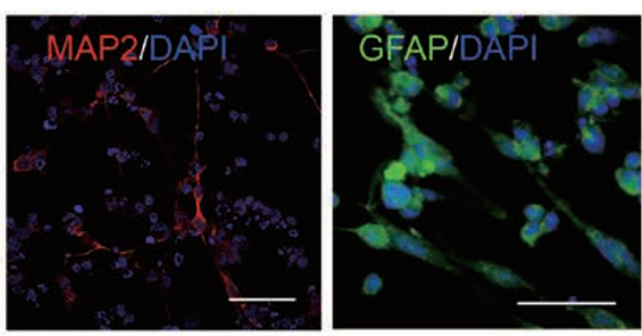
following VCR-treatment under hypoxia. Morphological changes of VCR-treated TTFs were also similar to those in VCR-treated MEFs when these cells were further cultured in NEM supplemented with heparin, EGF and bFGF for 7-10 days (Figure 6B). Homogenous ciNPCs could be gradually achieved following passaging (Supplementary information, Figure S12). ciNPC p16 from TTFs had typical NPC morphology and neurosphereforming ability. Expression of NPC marker genes Nestin, Sox2, Pax6 and Blbp was detected by immunofluorescent staining (Figure 6C) or quantified by real-time RTPCR analysis (Figure 6D). Furthermore, the TTF-derived ciNPCs could be induced to differentiate into $\mathrm{GFAP}^{+}$ astrocytes, $\mathrm{Tuj}^{+} / \mathrm{MAP}^{+}$neurons and $\mathrm{Olig} 2^{+} / \mathrm{Mbp}^{+}$ oligodendrocytes under defined differentiation conditions (Figure 6E). Therefore, the combination of VPA, CHIR99021, Repsox and hypoxia could directly convert different sources of mouse fibroblasts into ciNPCs.

As human urinary cells (hUCs) could be converted into iNPCs by introducing exogenous genes [21], we thereby tested whether hUCs can be induced into ciNPCs by the chemical cocktail VCR. 20 days post VCR treatment under $5 \% \mathrm{O}_{2}$, compact cell colonies similar to those formed in VCR-treated MEFs emerged from hUC culture (Figure 6F). Expression of Sox 2 was elevated on day 15 (Figure 6G). After being cultured for 5 passages in NEM, these VCR-induced intermediary cells began to show similar morphology to that of control iNPCs (induced by defined factors from hUCs as described previously [21]) (Figure 6H). These hUC-derived ciNPCs expressed NPC-specific genes including Sox2, Nestin, Sox 1 and Pax6 as monitored by qRT-PCR (Figure 6I) or immunofluorescent staining (Supplementary information, Figure S13A). Importantly, hUC-derived ciNPCs showed similar proliferation rate to that of control iNPCs (Supplementary information, Figure S13B) and could further differentiate into Tuj1 $1^{+} / \mathrm{MAP}^{+}$neurons and $\mathrm{GFAP}^{+}$as- trocytes in neural differentiation medium (Figure 6J). These results demonstrate that HUCs could be converted into NPCs by the chemical cocktail VCR.

The current available strategies to obtain patient-specific iNPCs include induction of transdifferentiation by sets of transcription factors from original hUCs [21] or induction of iNPCs from original fibroblasts through the human iPSC intermediate. Generation of human iNPCs through iPSCs would cost at least 3 months with the established protocol, whereas with our induction protocol, we can obtain similar amount of ciNPCs in much shorter time. Thus our results provide a potential alternative strategy to investigate patient-specific neural cells and related cell therapy.

\section{Discussion}

First of all, this is the first study demonstrating that direct lineage-specific conversion to NPCs can be achieved by chemical cocktails without introducing expression of exogenous genes. Although ciNPCs generated from mouse fibroblasts still retain some residual fibroblast epigenetic memory, these ciNPCs are highly similar to mouse brain-derived embryonic NPCs in terms of selfrenewal, proliferation and multipotency. It is of note that our induction strategy includes two major steps: an initial chemical-induced intermediary transition, followed by a lineage-specific induction. Considering that other cell lineages, such as cardiomyocytes and endothelial cells, can also be induced directly from mouse fibroblasts by defined factors [44-46], and differentiation of stem cells to different cell types is practicable in vitro, it should be possible to generate other desired cell types from differentiated somatic cells with similar strategies by using chemical cocktails and lineage-specific conditions.

Second, we found that inhibition of HDACs, TGF- $\beta$ and GSK-3 by diverse inhibitors was able to convert dif-

Figure 6 Generation and characterization of ciNPCs from mouse TTFs and human urinary cells. (A) Expression levels of pluripotent genes in TTFs treated with VCR under hypoxia were monitored by qRT-PCR analysis. All sample data are normalized to that of d0, which is considered as 1. (B) Morphology of TTFs and ciNPCs at passage 1 induced from TTFs. (C) Morphology and expression of Nestin, Sox2 and Pax6 ciNPC at passage 16 induced from TTFs. (D) qRT-PCR analysis of NPCspecific genes of TTF-derived ciNPCs at passage 16. All sample data are normalized to that of TTFs, which is considered as 1. (E) Expression of marker genes GFAP (astrocyte), Tuj1 (neuron), MAP2 (neuron), Olig2 (oligodendrocyte) and Mbp (oligodendrocyte) in TTF-derived ciNPCs p16 cultured in differentiation medium. (F) Phase-contrast images of human urinary cells (hUCs) before and after VCR treatment under $5 \% \mathrm{O}_{2}$. (G) Expession of pluripotent genes in hUCs treated with VCR under $5 \% \mathrm{O}_{2}$ for different days (d) was monitored by qRT-PCR analysis. All sample data are normalized to that of d0, which is considered as 1. (H) Morphology of hUC-derived ciNPCs at passage 5 cultured in monolayer or in suspension and control iNPCs cultured in monolayer. iNPCs were induced from human urinary cells by defined factors. (I) Expression of NPC-specific genes quantified by qRT-PCR analysis. All sample data are normalized to that of hUCs, which is considered as 1. (J) Expression of marker genes GFAP (astrocyte), Tuj1 (neuron) and MAP2 (neuron) in hUC-derived ciNPCs p5 cultured in differentiation medium. Nuclei were counterstained with DAPI. Scale bars represent $50 \mu \mathrm{m}$. Data are represented as the mean \pm SEM. Representative images from at least three independent experiments were shown. 
ferentiated somatic cells into intermediary cells under physiological hypoxic conditions. This process is accompanied by activation of endogenous Sox 2 expression. It is reported that Sox2 in combination with other transcription factors or even Sox 2 alone can convert somatic cells into neural cells or multipotent NPCs $[14,18,19$, 22]. Thus these three essential signaling pathways might coordinate to modulate Sox2-controlled gene expression and thereby promote the desired transition [47]. In addition, our cDNA array analysis revealed that genes that are known to be regulated by these pathways show very similar expression patterns in ciNPCs and control NPCs, which are significantly different from that in MEFs, further supporting the idea that activation of a defined set of genes by these pathways in concert are critical for the successful transition of MEFs to NPCs. However, the precise regulatory mechanisms remain to be investigated.

Third, in our study, we found that a physiological hypoxic condition is essential for the initial transition process. However, cobalt chloride known to induce cellular hypoxic response could not replace the hypoxic culture conditions to promote cell transition (data not shown), suggesting that the exact pathways activated under the physiological hypoxic condition need to be identified. Nevertheless, it is of note that although standard cell culture is performed at ambient $\mathrm{O}_{2}$ level $(21 \%)$, the actual mammalian tissue oxygen levels range from $1 \%$ to $5 \%$ [48]. Furthermore, a physiological hypoxic condition is also known to be one of the key beneficial niche features for stem cells in vivo [49]. Thus, it would be of great interest to test whether these chemical cocktails could facilitate cell lineage conversion in vivo.

Fourth, we also found that human ciNPCs can be generated from HUCs with the same chemical cocktail. Our study thus provides a possible strategy to produce patient-specific NPCs for treating neural diseases including Alzheimer's disease, Parkinson's disease, as well as other conditions such as that caused by ischemia or genetic deficiencies.

\section{Materials and Methods}

\section{Cell culture}

Primary MEFs were isolated from E13.5 mouse embryos as previously described [17]. Briefly, head, limbs, visceral tissues, gonads and vertebral column were removed; the remaining parts were cut into pieces, and trypsinized. Isolated MEFs were expanded till passage 3 and then used for further experiments. Mouse TTFs were isolated from C57BL/6 neonate on day 3 . Briefly, the front $1 / 5$ part of tail was cut into pieces and cultured for 6 days. Cells migrated out from the tail-tip pieces were passaged till passage 3 and then used for further experiments. Mouse MEFs and TTFs were maintained in DMEM (Life Technologies,
C11965) supplemented with 10\% FBS (PAA Laboratories, A15101), $1 \mathrm{mM}$ GlutaMAX (Life Technologies, 35050-061) and 0.1 $\mathrm{mM}$ non-essential amino acid (NEAA, Millipore, TMS-001-C) at $37{ }^{\circ} \mathrm{C}$ with $5 \% \mathrm{CO}_{2}$. Mouse NPCs were derived from E12.5 mouse embryos and expanded in neural expansion medium (NEM) (Millipore, SCM008) supplemented with $30 \mathrm{ng} / \mathrm{ml}$ heparin, $20 \mathrm{ng} / \mathrm{ml}$ EGF and $20 \mathrm{ng} / \mathrm{ml} \mathrm{bFGF}$ as described [50]. HUCs were collected and cultured in REGM (Lonza, CC-4127) as described [21, 51].

\section{Generation of ciNPCs}

For neural progenitor cell induction from MEFs and TTFs, initial cells cultured in DMEM for $24 \mathrm{~h}$ were transferred into KSR medium including knockout DMEM (Life Technologies, 10829018), 15\% knockout serum replacement (Life Technologies, 10828), 1\% NEAA (Life Technologies, 35050), 1\% GlutaMax (Life Technologies, 35050-061), 1\% sodium pyruvate (Life Technologies, 11360), $0.1 \mathrm{mM} \beta$-mercaptoethanol (Life Technologies, 21985-023) and $1000 \mathrm{U} / \mathrm{ml}$ leukemia inhibitory factor (LIF) (Chemicon, ESG1107). Cells were cultured at $37{ }^{\circ} \mathrm{C}$ under $5 \% \mathrm{O}_{2}$ (hypoxia) and $5 \% \mathrm{CO}_{2}$. Medium containing chemical compounds was changed every 5 days. For ciNPC induction from human cells, urinary cells were plated on Matrigel-coated six-well plates in REGM. Two days after seeding, medium was switched into mTeSR (Stem Cell Technologies, 05850 / 05896) with chemical cocktails and cultured at $37{ }^{\circ} \mathrm{C}$ under $5 \% \mathrm{O}_{2}$ (hypoxia) and $5 \%$ $\mathrm{CO}_{2}$. Medium was changed every five days. When compact cell colonies formed from mouse fibroblasts or HUCs, cell mixtures containing colonies were further cultured in NEM with growth factors. ciNPCs were further enriched by rounds of neurosphere suspension culture.

\section{Differentiation of ciNPCs in vitro}

ciNPCs $\mathrm{p} 5$ or $\mathrm{p} 13$ derived from mouse fibroblasts were cultured in NEM with EGF $(20 \mathrm{ng} / \mathrm{ml})$ and bFGF $(20 \mathrm{ng} / \mathrm{ml})$. For general neural differentiation, 20000 ciNPCs were plated onto PDL/ Laminin-coated 24-well plates in N2B27 medium (DMEM:F12, $1 \% \mathrm{~N} 2,2 \% \mathrm{~B} 27$ ) without EGF and bFGF. Robust astrogenesis was induced by adding BMP4 (50 ng/ml; R\&D Biosystems) and $1 \%$ FBS to N2B27 medium without growth factors. For neuronal differentiation, ciNPCs were plated onto PDL/Laminin-coated coverslips in neural differentiation medium (neural basal medium, $2 \%$ B27, $1 \% \mathrm{~N} 2,10 \mathrm{ng} / \mathrm{ml}$ BDNF, $10 \mathrm{ng} / \mathrm{ml} \mathrm{GDNF}, 10 \mathrm{ng} / \mathrm{ml}$ IGF-1, $1 \mu \mathrm{M}$ cAMP, $200 \mu \mathrm{M}$ ascorbic acid). The expression of neuronal markers was monitored and electrophysiological analysis was performed at the indicated time points. For oligodendrocyte differentiation, 20000 cells were plated onto PDL/Laminin-coated coverslips and cultured in N2B27 medium with bFGF $(10 \mathrm{ng} / \mathrm{mL}$; Invitrogen) and PDGF-AA (10 ng/mL; Peprotech) for 7 days and then with T3 (100 ng/mL; Sigma-Aldrich) for 5 days.

For hUC-derived ciNPC p11 neuronal differentiation, neurospheres were dissociated with accutase (Life Technologies) and 10000 cells were plated on poly-L-ornithine/laminin-coated coverslip. On the next day, EGF and bFGF were removed and neurotrophic factors including BDNF, GDNF, IGF (all at $10 \mathrm{ng} / \mathrm{mL}$ ) and $100 \mathrm{nM}$ cAMP, $200 \mathrm{ng} / \mathrm{mL}$ ascorbic acid were added to the culture medium. The neuronal differentiation medium was changed every 2 days. Two weeks later, expression of neuron markers were detected, and about 30 days later, expression of astrocyte marker could be detected. 
Alkaline phosphatase analysis

Prior to staining, cells were fixed with $4 \%$ paraformaldehyde (PFA) in PBS for 2 min. The alkaline phosphatase (AP) staining was performed using alkaline phosphatase kits (Sigma-Aldrich, 85L3R) following the manufacturer's protocol. Images were acquired using Zeiss Observer Z1.

\section{Immunofluorescent staining}

Cells cultured on glass coverslips were fixed in 4\% PFA solution for $10 \mathrm{~min}$ then incubated in blocking buffer ( $1 \%$ bovine serum albumin in PBS) with or without $0.5 \%$ Triton X-100 for 30 $\mathrm{min}$ at room temperature (RT). Afterwards, samples were incubated with primary antibodies at $4{ }^{\circ} \mathrm{C}$ overnight and then with appropriate fluorescent probe-conjugated secondary antibodies for $1 \mathrm{~h}$ at RT. Nuclei were counterstained with DAPI. Images were taken by fluorescence microscope (Olympus IX71) or Leica SP-8 confocal microscope. Specific primary antibodies used include Nestin (1:1 000, Millipore, MAB5326), Sox2 (1:200, R\&D, AF2018), Pax6 (1:500, Covance, RPB-278P), Ki67 (1:500, Abcam, ab15580), GFAP (1:1 000, Dako, Z0334), Tuj1 (1:500, Covance, MMS435P), MAP2 (1:250, Millipore, AB5622), Mbp (1:250, Covance, SMI94), Olig2 (1:400, Santa Cruz, sc-19969), NeuN (1:200, Millipore, MAB377), GAD67 (1:200, Millipore, MAB5406), Synapsin (1:200, Millipore, AB1543) and Glutamate (1:200, Millipore, MAB5304).

For immunostaining analysis of neurospheres, the culture medium containing neurospheres was first transferred into $15 \mathrm{ml}$ conical tube, allowing the neurospheres to settle down by gravity. The neurosphere collection was then fixed with $4 \%$ PFA for 15 min at RT, and incubated in $5 \mathrm{ml} 30 \%$ sucrose overnight at $4{ }^{\circ} \mathrm{C}$ till settling down. The neurosphere pellets were transferred into tissue freezing medium (Leica, 0201 08926) on the cryostat chuck. Neurosphere sections with $10 \mu \mathrm{M}$ thickness were prepared, bagged by foil and kept at $-80{ }^{\circ} \mathrm{C}$ for further analysis.

Mouse brain sections were prepared as described. In brief, cardiac PBS-perfused mouse brains were perfused with 4\% PFA. After being cryopreseved in $30 \%$ sucrose, the mouse brains were cryosectioned at $20 \mu \mathrm{m}$ for further immunofluorescent staining analysis.

\section{Microarray analysis}

Whole genome expression analysis was performed by Shanghai OE Biotech Co., Ltd according to the protocol of one-color microarray-based gene expression analysis from Agilent Technology. Briefly, RNA samples were isolated using TRIzol (Sigma-Aldrich, T9424) following the manufacturer's instructions and RNA integrity was assessed by Agilent 2100 bioanalyzer. Two-hundred nanograms of total RNA per sample was added for labeling reaction by one-color quick amp labeling Kit (Agilent, 5190-2305). Labeled/ amplified RNA was purified by RNeasy mini kit (Qiagen, 74104). cDNA array chips for $8 \times 60 \mathrm{~K}$ array from Agilent Technologies (Cat\#: G4852A) and Agilent gene expression hybridization kit (Agilent $\mathrm{p} / \mathrm{n} 5188-5242$ ) were used. After hybridization at $65^{\circ} \mathrm{C}$ for $17 \mathrm{~h}$ and washing steps, microarray slides were scanned by Agilent microarray scanner (Agilent Technologies, USA). Feature Extraction software (version10.7.1.1, Agilent Technologies) was used to analyze array images to get raw data. GeneSpring were employed to finish the basic analysis with the raw data. To begin, the raw data was normalized with the quantile algorithm. The probes that at least $100 \%$ of the values in any 1 out of all conditions have flags in "Detected" were chosen for further data analysis. Differentially expressed genes were then identified through fold change value cut off at 10. Afterwards, GO analysis and KEGG analysis were applied to determine the roles of these differentially expressed mRNAs. 55821 probes for 39430 genes from entrez-gene database were detected.

\section{Quantitative real-time $P C R$}

Total RNAs were extracted from cells using Trizol reagent according to the manufacturer's instructions (Sigma-Aldrich, T9424). RNA was reverse-transcribed to cDNA using random hexamers and M-MLV Reverse Transcriptase (Promega). cDNA samples were then mixed with 2× PCR Mix (Qiagen) and Eva Green (Biotium) and subjected to real-time quantitative PCR analysis with an MX3000P Stratagene PCR machine. The relative expression values were normalized against the internal controls (HPRT). Primers used were listed in Supplementary information, Table S2.

\section{Electrophysiological analysis}

Whole-cell patch clamp recordings were carried out on ciNPCderived neurons. Recordings were made using Multiclamp 700B amplifier (Molecular Devices). The bath was constantly perfused with fresh artificial cerebrospinal fluid (ACSF) at RT. The ACSF contained (in mM) $126 \mathrm{NaCl}, 3 \mathrm{KCl}, 1.25 \mathrm{KH}_{2} \mathrm{PO}_{4}, 1.3 \mathrm{MgSO}_{4}$, $3.2 \mathrm{CaCl}_{2}, 26 \mathrm{NaHCO}_{3}$, and 10 glucose, bubbled with $95 \% \mathrm{O}_{2} / 5 \%$ $\mathrm{CO}_{2}$. Signals were sampled at $10 \mathrm{kHz}$ with a $2 \mathrm{kHz}$ low-pass filter. The whole-cell capacitance was fully compensated. Recordings with $\mathrm{Ra}>50 \mathrm{M}$ or fluctuation $>20 \%$ were excluded. The intracellular solution contained (in $\mathrm{mM}$ ): $93 \mathrm{~K}$-gluconate, $16 \mathrm{KCl}, 2$ $\mathrm{MgCl}_{2}, 10$ HEPES, 4 ATP-Mg, 0.3 GTP-Na, 10 creatine phosphate, $0.5 \%$ Alexa Fluor 568 hydrazide (Invitrogen) ( $\mathrm{pH} 7.25$, 290/300 mOsm), and 0.4\% neurobiotin (Invitrogen). Membrane potentials were hold around $-70 \mathrm{mV}$, and step currents with an increment of $2 \mathrm{pA}$ were injected to elicit action potentials. A ramp protocol (from -70 to $+70 \mathrm{mV}$ ) was used to elicit inward sodium current and outward potassium currents. Data were analyzed using pClamp10 (Clampfit).

\section{In vivo transplantation}

In vivo transplantation was performed as previously described [52]. Briefly, uterine horns of E13.5 gestation stage pregnant C57BL/6 mice were maintained in pathogen-free condition. $2 \mu 1$ PBS containing around 20 GFP-ciNPC neurospheres with neurosphere diameter less than $80 \mu \mathrm{m}$ was injected into the embryonic cerebral ventricle through a bevelled, calibrated glass micropipette. After that, the uterine horns were replaced, the peritoneal cavity was lavaged with $10 \mathrm{~mL}$ warm PBS containing antibiotics and the wound was closed. 1 week or 1 month after transplantation, mice were anesthetized on ice or with pentobarbital sodium and brains section were prepared as described above for further analysis.

\section{Animal maintenance}

All mice were given ad libitum access to food and water. All experiments were in accordance with the National Institutes of Health Guide for the Care and Use of Laboratory Animals and were approved by the Biological Research Ethics Committee, Shanghai Institutes for Biological Sciences, Chinese Academy of Sciences. 


\section{Statistical analysis}

All quantified data were statistically analyzed and presented as mean \pm SEM. Unless otherwise stated, one-way ANOVA was used to calculate statistical significance with $P$ values are detailed in the text and figure legends.

\section{Acknowledgments}

We thank all members of the lab for sharing reagents and advice. We thank Dr Yi Sun (Tongji University, China) for helping with neural differentiation assay. This work was supported by Chinese Academy of Sciences (XDA01010302, 2012KIP301), the Ministry of Science and Technology (2014CB964802, 2011CB910202), the National Natural Science Foundation of China $(31371419,31301129)$ and Shanghai Municipal Commission for Science and Technology (12ZR1452300) and Ministry of Health (2012BAI10B03).

\section{References}

1 Gilbert S. Developmental Biology. 6th Edition: Sunderland: Sinauer Associates 2000.

2 Gurdon JB, Elsdale TR, Fischberg M. Sexually mature individuals of Xenopus laevis from the transplantation of single somatic nuclei. Nature 1958; 182:64-65.

3 Campbell KH, McWhir J, Ritchie WA, Wilmut I. Sheep cloned by nuclear transfer from a cultured cell line. Nature 1996; 380:64-66.

4 Miller RA, Ruddle FH. Pluripotent teratocarcinoma-thymus somatic cell hybrids. Cell 1976; 9:45-55.

5 Blau HM, Chiu CP, Webster C. Cytoplasmic activation of human nuclear genes in stable heterocaryons. Cell 1983; 32:1171-1180.

6 Takahashi K, Yamanaka S. Induction of pluripotent stem cells from mouse embryonic and adult fibroblast cultures by defined factors. Cell 2006; 126:663-676.

7 Vierbuchen T, Wernig M. Direct lineage conversions: unnatural but useful? Nat Biotechnol 2011; 29:892-907.

8 Martino G, Pluchino S. The therapeutic potential of neural stem cells. Nat Rev Neurosci 2006; 7:395-406.

9 Zhu JH, Zhou LF, XingWu F. Tracking neural stem cells in patients with brain trauma. New Engl J Med 2006; 355:23762378.

10 Uchida N, Buck DW, He DP, et al. Direct isolation of human central nervous system stem cells. Proc Natl Acad Sci USA 2000; 97:14720-14725.

11 Tropepe V, Hitoshi S, Sirard C, Mak TW, Rossant J, van der Kooy D. Direct neural fate specification from embryonic stem cells: A primitive mammalian neural stem cell stage acquired through a default mechanism. Neuron 2001; 30:65-78.

12 Chambers SM, Fasano CA, Papapetrou EP, Tomishima M, Sadelain M, Studer L. Highly efficient neural conversion of human ES and iPS cells by dual inhibition of SMAD signaling. Nat Biotechnol 2009; 27:275-280.

13 Reubinoff BE, Itsykson $\mathrm{P}$, Turetsky $\mathrm{T}$, et al. Neural progenitors from human embryonic stem cells. Nat Biotechnol 2001; 19:1134-1140.

14 Han DW, Tapia N, Hermann A, et al. Direct reprogramming of fibroblasts into neural stem cells by defined factors. Cell Stem
Cell 2012; 10:465-472.

15 Kim J, Efe JA, Zhu SY, et al. Direct reprogramming of mouse fibroblasts to neural progenitors. Proc Natl Acad Sci USA 2011; 108:7838-7843.

16 Kumar A, Declercq J, Eggermont K, Agirre X, Prosper F, Verfaillie CM. Zic3 induces conversion of human fibroblasts to stable neural progenitor-like cells. J Mol Cell Biol 2012; 4:252-255.

17 Lujan E, Chanda S, Ahlenius H, Sudhof TC, Wernig M. Direct conversion of mouse fibroblasts to self-renewing, tripotent neural precursor cells. Proc Natl Acad Sci USA 2012; 109:2527-2532.

18 Ring KL, Tong LM, Balestra ME, et al. Direct reprogramming of mouse and human fibroblasts into multipotent neural stem cells with a single factor. Cell Stem Cell 2012; 11:100-109.

19 Thier M, Worsdorfer P, Lakes YB, et al. Direct conversion of fibroblasts into stably expandable neural stem cells. Cell Stem Cell 2012; 10:473-479.

20 Tian C, Ambroz RJ, Sun L, et al. Direct conversion of dermal fibroblasts into neural progenitor cells by a novel cocktail of defined factors. Curr Mol Med 2012; 12:126-137.

21 Wang LH, Wang LL, Huang WH, et al. Generation of integration-free neural progenitor cells from cells in human urine. Nat Methods 2013; 10:U84-U124.

22 Sheng C, Zheng Q, Wu J, et al. Direct reprogramming of Sertoli cells into multipotent neural stem cells by defined factors. Cell Res 2012; 22:208-218.

23 Hou P, Li Y, Zhang X, et al. Pluripotent stem cells induced from mouse somatic cells by small-molecule compounds. Science 2013; 341:651-654.

24 Obokata H, Wakayama T, Sasai Y, et al. Stimulus-triggered fate conversion of somatic cells into pluripotency. Nature 2014; 505:641-647.

25 Huangfu D, Maehr R, Guo W, et al. Induction of pluripotent stem cells by defined factors is greatly improved by smallmolecule compounds. Nat Biotechnol 2008; 26:795-797.

26 Ichida JK, Blanchard J, Lam K, et al. A small-molecule inhibitor of Tgf- $\beta$ signaling replaces Sox 2 in reprogramming by inducing Nanog. Cell Stem Cell 2009; 5:491-503.

27 Li W, Zhou H, Abujarour R, et al. Generation of humaninduced pluripotent stem cells in the absence of exogenous Sox2. Stem Cells 2009; 27:2992-3000.

28 Maherali N, Hochedlinger K. Tgf $\beta$ signal inhibition cooperates in the induction of iPSCs and replaces Sox2 and cMyc. Curr Biol 2009; 19:1718-1723.

29 Shi Y, Desponts C, Do JT, Hahm HS, Schöler HR, Ding S. Induction of pluripotent stem cells from mouse embryonic fibroblasts by Oct 4 and Klf4 with small-molecule compounds. Cell Stem Cell 2008; 3:568-574.

30 Yoshida Y, Takahashi K, Okita K, Ichisaka T, Yamanaka S. Hypoxia enhances the generation of induced pluripotent stem cells. Cell Stem Cell 2009; 5:237-241.

31 Chen T, Yuan D, Wei B, et al. E-cadherin-mediated cell-cell contact is critical for induced pluripotent stem cell generation. Stem Cells 2010; 28:1315-1325.

$32 \mathrm{Li} \mathrm{W}$, Tian E, Chen ZX, et al. Identification of Oct4-activating compounds that enhance reprogramming efficiency. Proc Natl Acad Sci USA 2012; 109:20853-20858.

33 Lee J, Sayed N, Hunter A, et al. Activation of innate immunity 
is required for efficient nuclear reprogramming. Cell 2012; 151:547-558.

34 McKay R. Stem cells in the central nervous system. Science 1997; 276:66-71.

35 Gritti A, Parati EA, Cova L, et al. Multipotential stem cells from the adult mouse brain proliferate and self-renew in response to basic fibroblast growth factor. J Neurosci 1996; 16:1091-1100

36 Kim K, Doi A, Wen B, et al. Epigenetic memory in induced pluripotent stem cells. Nature 2010; 467:285-290.

37 Briscoe J, Pierani A, Jessell TM, Ericson J. A homeodomain protein code specifies progenitor cell identity and neuronal fate in the ventral neural tube. Cell 2000; 101:435-445.

38 Goulding MD, Chalepakis G, Deutsch U, Erselius JR, Gruss P. Pax-3, a novel murine DNA binding protein expressed during early neurogenesis. EMBO J 1991; 10:1135-1147.

39 Kawakami A, Kimura-Kawakami M, Nomura T, Fujisawa H. Distributions of PAX6 and PAX7 proteins suggest their involvement in both early and late phases of chick brain development. Mech Dev 1997; 66:119-130.

40 Simeone A, Acampora D, Gulisano M, Stornaiuolo A, Boncinelli E. Nested expression domains of four homeobox genes in developing rostral brain. Nature 1992; 358:687-690.

41 Davis CA, Joyner AL. Expression patterns of the homeo boxcontaining genes En-1 and En-2 and the proto-oncogene int-1 diverge during mouse development. Genes Dev 1988; 2:17361744.

42 Reynolds BA, Weiss S. Generation of neurons and astrocytes from isolated cells of the adult mammalian central nervous system. Science 1992; 255:1707-1710.

43 Gottlicher M, Minucci S, Zhu P, et al. Valproic acid defines a novel class of HDAC inhibitors inducing differentiation of transformed cells. EMBO J 2001; 20:6969-6978.

44 Margariti A, Winkler B, Karamariti E, et al. Direct reprogramming of fibroblasts into endothelial cells capable of angiogenesis and reendothelialization in tissue-engineered vessels. Proc
Natl Acad Sci USA 2012; 109:13793-13798.

45 Efe JA, Hilcove S, Kim J, et al. Conversion of mouse fibroblasts into cardiomyocytes using a direct reprogramming strategy. Nat Cell Biol 2011; 13:215-222.

46 Kurian L, Sancho-Martinez I, Nivet E, et al. Conversion of human fibroblasts to angioblast-like progenitor cells. Nat Methods 2013; 10:77-83.

47 Wang S, Xia P, Ye B, Huang G, Liu J, Fan Z. Transient activation of autophagy via Sox2-mediated suppression of mTOR is an important early step in reprogramming to pluripotency. Cell Stem Cell 2013; 13:617-625.

48 Carreau A, El Hafny-Rahbi B, Matejuk A, Grillon C, Kieda C. Why is the partial oxygen pressure of human tissues a crucial parameter? Small molecules and hypoxia. J Cell Mol Med 2011; 15:1239-1253.

49 Mohyeldin A, Garzón-Muvdi T, Quiñones-Hinojosa A. Oxygen in stem cell biology: a critical component of the stem cell niche. Cell Stem Cell 2010; 7:150-161.

50 Ebert AD, McMillan EL, Svendsen CN. Isolating, expanding, and infecting human and rodent fetal neural progenitor cells. Curr Protoc Stem Cell Biol 2008; Chapter 2:Unit 2D.2.

51 Zhou T, Benda C, Dunzinger S, et al. Generation of human induced pluripotent stem cells from urine samples. Nat Proto 2012; 7:2080-2089.

$52 \mathrm{Yu} \mathrm{YC,} \mathrm{He} \mathrm{S,} \mathrm{Chen} \mathrm{S,} \mathrm{et} \mathrm{al.} \mathrm{Preferential} \mathrm{electrical} \mathrm{coupling}$ regulates neocortical lineage-dependent microcircuit assembly. Nature 2012; 486:113-117.

(Supplementary information is linked to the online version of the paper on the Cell Research website.)

(c) (1) (3) This work is licensed under the Creative Commons Attribution-NonCommercial-No Derivative Works 3.0 Unported License. To view a copy of this license, visit http:// creativecommons.org/licenses/by-nc-nd/3.0 